\title{
El cese de relación laboral en Ecuador por causa del Covid 19
}

\section{The termination of employment in Ecuador due to Covid 19}

Ligia Maricela Niama Rivera. ${ }^{1}$, Carlos Iván Villalva Heredia. ${ }^{2}$, Mónica Paulina Terán Pérez. $^{3}$, Edison Fernando Campos Collaguazo. ${ }^{4}$

\begin{abstract}
.
DOI: $\underline{\text { https://doi.org/10.33262/concienciadigital.v3i3.1.1381 }}$
\end{abstract}

The review of information from these 6 months from the start of the pandemic in our country has as its present point of concern collects a possible mark on which could be the collective blow caused by the real health outburst of COVID19. Based on the statistics registered in estates such as the Ministry of Labor, both in social security disaffiliations and based on the apparent emotion about the job (analyzing its characteristics and madrigal, it is determined which will be the most affected groups and / or those who are They are in a more delicate work environment. The coronavirus is reaching more victims in Ecuador, among them are companies without cash flow and workers who lose their jobs due to lack of liquidity. The country had a rate of underemployment and unemployment of the 24.6 percent in December 2019. Being this one that currently has 17.5 million inhabitants and about 8.5 million are economically active, but not all produce or receive a formal salary, the crisis that we face due to this pandemic has been aggravated by the bankruptcy of companies in recent months, calculating that nearly 80,000 workers from public and private companies have been laid off in their functions and are at home without salary or severance pay.

keywords: Salary, Employment relationship, Termination, Covid

\footnotetext{
${ }^{1}$ Escuela Superior Politécnica de Chimborazo, Riobamba, Ecuador, ligia.niama@espoch.edu.ec (iD) https://orcid.org/0000-0002-1818-0041

${ }^{2}$ Docente Educación Media Superior. Riobamba, Ecuador, ivan.villalva@educación.gob.ec (iD) https://orcid.org/0000-0002-4042-943x

${ }^{3}$ Docente Educación Media Superior, Riobamba Ecuador, monyxioma@hotmail.com

${ }^{4}$ Grupo INCORHP, Riobamba Ecuador, edic84@ hotmail.com
} 


\section{Resumen}

La revisión de información de estos 6 meses a partir del inicio de la pandemia en nuestro país tiene como presente apunte de incumbencia recoge una posible marca sobre la cuál podría ser el trastazo colectivo provocado por el real arrebato sanitario del COVID19. En base a las estadísticas registradas en estamentos como ministerio de trabajo, tanto en desafiliaciones a la seguridad Social y en base a la aparente emoción sobre el oficio (analizando sus características y madrigal se determinan cuáles serán los colectivos más perjudicados y/o aquellos que se encuentran en un ámbito laboral más delicado. El coronavirus está alcanzando a más víctimas en Ecuador entre ellas se trata de las empresas sin flujo de caja y los trabajadores que pierden su empleo por falta de liquidez. El país presentaba una tasa de subempleo y desempleo del 24.6 por ciento en diciembre de 2019. Siendo este que en su actualidad cuenta con 17.5 millones de habitantes y cerca de 8.5 millones son económicamente activos, pero no todos producen ni perciben un salario formal, la crisis que enfrentamos por esta pandemia se ha agravado por el quiebre de empresas durante los últimos meses, calculando que cerca de 80.000 trabajadores de empresas públicas y privadas, han sido cesados en sus funciones y están en casa sin salario, ni indemnización por despido.

Palabras claves: Salario, Relación laboral, Cese, Covid

\section{Introducción}

En el contexto de las medidas de inhibición del COVID-19, se prevé que el mercado laboral en sector negocio, los comedores y hospedajes, la producción industrial se cuente entre el más sacudido, luego que la responsabilidad en lista agraria como pecuaria (ineludible hacia la firmeza natural y, colectivamente, con la emergencia de motivar el distanciamiento físico en las tareas a realizar) está con un daño de detrimento (temporal) de alti-bajo como manifiesta la Cepal y la OIT cruzando el primer trimestre de este año. A excepción igualmente en el rastro persisten diversidades que siguen en marcha como los que comercializan surtidos de exigencia básica (provisiones, limpieza individual, medicamentos, etcétera.), lo que involucra que en las secciones como locales, autoservicios y establecimientos de droguería el espacio se habría sostenido.

Entre las diferentes variedades de ocupación, en el contexto de las medidas de contención del COVID-19 el compromiso por cuenta propia tiende a ser más deteriorado que el deber asalariado, dueños de locales especialmente, sin ningún inconveniente más, para escenarios en que este encargo se efectúa a modo actividad informal. A ello favorece que su diligencia en gran envergadura la establece en amparo limitado digno a las proporcionadas barreras de la movilidad. Por lo tanto, se puede llevar a que, paradójicamente a los métodos acostumbrados en argumentos de dificultades económicas, en el flaco década la musicalidad del área bala perdida en lugar general se contraiga. (Thomas, 2020) 
No obstante, esta sería un entorno transitorio, ofrecido que con la anulación de dichas disposiciones no solo regresarían a desempeñarse en el mercado inconstante los individuos que tuvieron que menoscabar de su movimiento corriente, más aún se incluirán algunos grupos de trabajadores.

Este podría alcanzar a ser la casualidad de trabajadores formales que perdieron su región y jóvenes nuevos entrantes al establecimiento gremial u otros cuerpos del hogar que necesiten contribuir al fruto ordinario. De esta manera, se examinaría el riesgo de un boom del mercado laboral.

El COVID-19 perjudicarán en mayor o menor nivel, de acorde a la duración que vaya dando en el país y el mundo, la posibilidad de que muchas pymes empresas formales. Estas, ya de por sí están en perjuicio estructural por la falla tecnológica que es notorio entre empresas de diferente tamaño en el contexto de la digitalización por lo que se ha planteado que el fomento del uso de tecnologías digitales en las empresas y con ello a tener menos personal que cubra ciertos puestos de trabajo (CEPAL, 2020). El entorpecimiento de una cantidad de estas empresas no se entrañaría una profundización de procesos de agrupación; igualmente se asesinarían de forma inmortal cierta de la cantidad de empleos formales accesibles para personas de niveles intermedios de aprendizaje definitivo, con lo cual se agudizaría la tendencia de juntar el lado de este tipo la de vigor de trabajo en sectores de innoble productividad y de mercado informal.

Durante la emergencia sanitaria que se continúa viviendo en Ecuador, la gran parte de las empresas tuvieron que suspender sus actividades como indica el decreto presidencial $\mathrm{N}^{\circ}$ 1017. Es por ello que ciertos sectores se han visto afectados económicamente desde marzo, cuando empezó la emergencia sanitaria. En ese contexto, una preocupación principal ha sido situación económica de los empleadores contra la estabilidad laboral de los trabajadores, motivo por el cual el Ministerio de Trabajo emitió Acuerdos Ministeriales que permiten que los empleadores adopten por alternativas laborales no presenciales, y modificación en la relación laboral con el objeto de no incurrir en posibles despidos intempestivo.

Si bien es cierto nos ha brindado algunas directrices como:

- Acuerdo Ministerial MDT-2020-076: Directrices para la aplicación del teletrabajo emergente.

- Acuerdo Ministerial MDT-2020-077: Directrices para aplicación de la reducción, modificación, o suspensión de la jornada laboral.

Sin embargo, para las empresas que no pudiesen acogerse a las directrices establecidas en los acuerdos ministeriales se estableció el acuerdo ministerial MDT-081 
- Acuerdo Ministerial No. MDT-2020-081: Directrices para la aplicación de la causal 6 del artículo 169 del Código de Trabajo.

\section{Desarrollo.}

La emergencia sanitaria provocada por la indisposición del COVID-19 tiende a convertirse en una demarcación trascendental que marcará el siglo XXI por las consecuencias sociales y económicas sobre inmensas masas de la población mundial. Es así que los grandes retos socioeconómicos trazados por algunos países de Latinoamérica, se verán dilatados por cuenta del conflicto fiscal que suponen las medidas de albur inesperadas en un cuadro de turbulencia financiera, de afligirse para la inversión extranjera, y primeramente, de presiones deficitarias en las cuentas comerciales a juicio de la contracción en la exigencia y los precios mundiales del Petro aceite (Cardona-Areanas \& Serna-Gómez, 2020), al igual que de otros productos básicos de la canasta exportadora. A esto se relaciona una coyuntura de recaudos tributarios inciertos debido a la desaceleración del utensilio fructífero y las rentas salariales, donde muy seguramente el movimiento de recaudos será deficitario en representación con los auxilios financieros que requerirá el arranque sanitario (Mundial, 2008) (Fedesarrollo, 2020)

La disrupción de la vitalidad cotidiana y de la acción laboral como resultado de las medidas de los gobiernos para afrontar la crisis sanitaria provocada por la pandemia del COVID-19 ha tenido múltiples consecuencias, mano para los trabajadores como para las organizaciones. Desde marzo de 2020, la rápida expansión del bacteria en la mayoría de los países de Europa y América y las medidas de distanciamiento social y cuarentena adoptadas han generado el cierre de una gran cantidad de empresas, negocios y comercios, han fervoroso las formas de tratar, especialmente, imponiendo el teletrabajo o el compromiso ancestral, se han imperceptible las horas de obligatoriedad y los salarios, y se han rescindido o redefinido las condiciones de un gran cifra de contratos, conmoviendo a millones de trabajadores/as de toda género.

Si acertadamente la circunstancia puede percibirse como un fortuna momentáneo, y buena constituyente de los y las trabajadoras esperan volver en si su lugar y las condiciones de cometido alteradas tras la arranque, las percepciones acerca de cómo se han ahijado estas medidas laborales, el sostenimiento más o menos largo de ciertas condiciones de obligatoriedad (por norma, el teletrabajo) y los efectos sufridos durante estos meses, pueden sobrevenir consecuencias profundas para las relaciones entre los individuos y las organizaciones. (Tapia, 2020)

\section{¿Covid-19 es considerado como causal terminación de contrato?}


La emergencia sanitaria provocada por el Covid-19 ha obligado a varios empleadores a desvincular a los trabajadores sin pagar indemnizaciones. Las empresas han sustentado la decisión, según denuncias ciudadanas, en el numeral 6 del artículo 169 del Código de Trabajo. (Código de Trabajo, 2017)

Esta norma establece que una de las causales para la terminación del contrato es el "caso fortuito o fuerza mayor" que son eventos imprevistos que impiden que una empresa siga trabajando.

Varios abogados en materia laboral, analizan el artículo 169 del código de trabajo. Según, Páez "El caso fortuito o fuerza mayor es un argumento legalmente establecido", pero considera que el empleador no puede usar de manera discrecional esta figura para dar por terminado un contrato de trabajo.

El abogado explica los riesgos que trae el justificar un despido intempestivo con el numeral 6 del artículo 169 del Código de Trabajo.

Luego de superar la emergencia sanitaria, cuando las empresas retomen sus operaciones, la empresa asumirá denuncias laborales que acarrearían el pago de indemnizaciones por despido intempestivo.

Páez recomienda a los empleadores no usar la figura del caso fortuito o fuerza mayor para desvincular personal sin pagar indemnizaciones, porque podrían afrontar en un futuro una serie de denuncias laborales.

\section{Metodología}

Según Alfonso Becerra, especialista en Derecho Laboral en diálogo con la Voz de América explicó que el Código del Trabajo establece una forma de terminación de contrato "por casos fortuitos y fuerza mayor". "Esta ha sido la figura que ha sido más utilizada en los últimos días por los empleadores aquí en el Ecuador". Admitió que esta "forma de terminación de la relación laboral (...) ha causado tanta controversia porque los trabajadores básicamente se van a sus casas sin pagos indemnizatorios ni modificatorios y tan solo con pagos de derechos adquiridos".

Según el Instituto Nacional de Estadística y Censos (INEC, 2010) el empleo pleno, es decir, quienes gozan de seguridad social y beneficios de Ley era del 38.5\% hasta finales de 2019. El gobierno calcula que al final de la pandemia 508.000 personas podrían estar solicitando el bono de desempleo creado por el Instituto Ecuatoriano de Seguridad Social (IESS) (Jácome, 2020)Varias empresas han reducido del 25 al 50\% el salario de sus trabajadores y regulado las jornadas laborales para no cerrar los servicios. 
Tabla 1.- Alternativas laborales

\begin{tabular}{lcl}
\hline \multicolumn{3}{c}{ Alternativas laborales } \\
& Por número de empresas y trabajadores \\
\hline & empresas & Teletrabajadores \\
Teletrabajo & 5448 & 402.094 \\
Reducción de horas & 8676 & 188.896 \\
Suspensión laboral & 34683 & 506.692 \\
Modificación laboral & 2137 & 26208 \\
\hline
\end{tabular}

Elaborado por los autores

Fuente: (Jácome, 2020)

En medio de este panorama, el 1 de mayo día del Trabajo los sindicatos protestaron a través de redes sociales señalando que las empresas están aprovechando el momento para despedir a sus trabajadores. Las protestas del mes de octubre de 2019 ya habían puesto al borde la economía de las pequeñas empresas en Ecuador (Pymes) y el COVID-19 ha sido el más reciente golpe (DerechoEcuador., 2020)

Durante los 160 días de inactividad, el sector productivo ha perdido 10.000 millones de dólares, lo que ha llevado a las empresas a declararse en quiebra y despedir a la gente.

Las autoridades de esta cartera de Estado dicen no contar con el cálculo de los despidos que se han dado, según los sectores económicos, pero revelan que de las casi 80.000 desvinculaciones laborales que se han dado a nivel nacional, la mayoría (45.667) llegó a darse por mutuo acuerdo entre las partes. Le siguen otras causales como la terminación dentro del periodo de prueba (9.422 casos); por fuerza mayor o caso fortuito (6.609) y los despidos intempestivos (4.226).

\section{Resultados.}

Los estudios realizados en las distintas empresas del país son las mismas que se acogerán al artículo 169, numeral 6, del Código del Trabajo el cual manifiesta que "para despedir a sus empleados alegando fuerza mayor o caso fortuito deben registrar esta información en el Sistema Único de Trabajo junto con los fundamentos que sustenten la terminación de estos contratos", (Código de Trabajo, 2017), según consta en el Acuerdo aprobado el 10 de abril pasado que a la vez reforma el Acuerdo Ministerial MDT-2017-135, en el que se regulan las formas de trabajo para casos de emergencia (E.U, 2020)

En las últimas semanas se conocieron compañías como:

- Confiteca

- The English Playhouse Cía. Ltda 


\section{- Florícolas}

Que prescindieron de parte de su personal alegando el art. 169.

En el reciente acuerdo se incluyen dos nuevas transitorias: la sexta y la séptima. Una dispone que "cuando el empleador, en razón de la emergencia sanitaria declarada, no le sea posible utilizar los mecanismos establecidos para realizar el pago de liquidaciones y/o de multas, podrá efectuar los mismos a través de transferencia bancaria con los datos que el Ministerio de Trabajo pondrá a disposición en su página oficial".

La otra señala que "el empleador que alegue la terminación del contrato individual de conformidad con la causal 6 (caso fortuito o fuerza mayor) deberá dentro de las 24 horas posteriores registrar en el Sistema Único de Trabajo los fundamentos que sustenten la terminación del contrato; además de notificar al trabajador...” (E.U, 2020).

La incorrecta aplicación genera sanciones la cual se menciona en el artículo 11 del acuerdo ministerial 089 sobre el procedimiento emergente de denuncias presentadas durante la declaratoria de estado de excepción.

El articulado indica sanciones de tres hasta veinte Salarios Básicos Unificados, conforme lo previsto en el artículo 7 del Mandato Constituyente.

\section{a. Edesa}

La empresa Edesa despidió el mes de abril a 327 trabajadores con la misma figura de caso fortuito o fuerza mayor. Esta fábrica tiene un capital de 19 millones de dólares, no pagó impuesto a la renta el año pasado, y en los últimos tres años sacó del país 15,2 millones de dólares.

Sus accionistas, según la Superintendencia de Compañías, son Inversiones Cisa, de Chile; y el Banco de Desarrollo del Ecuador.

Los afectados no aceptaron los valores de las liquidaciones determinados por la empresa por lo que presentaron demandas en el ministerio de Trabajo.

\section{b. Confiteca}

El 30 de marzo, al menos 140 personas fueron despedidas de Confiteca, una importante productora de dulces del Ecuador. De acuerdo con denuncias de varios trabajadores en redes sociales, la empresa les explicó los graves problemas económicos por los que atraviesa por el cierre de mercados locales e internacionales, y se acogió a un artículo del Código del Trabajo que invoca el caso fortuito o de fuerza mayor. 
La empresa explicó que se trató de una reestructuración, ya que las ventas y producción han caído muchísimo y que sus decisiones están amparadas en la ley. Aseguró que la gente que ha salido tiene la palabra de los empresarios de que cuando las operaciones se estabilicen serán los primeros en ser tomados en cuenta.

\section{c. Fábrica de Muebles Colineal}

La fábrica de muebles Colineal desvinculó a 600 trabajadores, muchos de los cuales no aceptaron la liquidación propuesta e interpusieron acciones legales. Los accionistas son Roberto Maldonado Álvarez y los hermanos María, Karla, Paola y Roberto Maldonado Chávez.

La empresa pagó por impuesto a la renta en los últimos tres años más de 2 millones de dólares y registró en el mismo período 474.793 dólares por pago de impuesto a la salida de divisas, es decir sacó del país 9,4 millones de dólares.

\section{d. Grand Hotel Guayaquil}

Uno de los casos más recientes fue el de Segundo Aguila, quien después de haber trabajado durante 39 años como chef en el Grand Hotel Guayaquil, fue notificado con el cese de funciones.

En el acta de finiquito se estableció una liquidación de USD 378,32, valor que corresponde a la remuneración de los días laborados en el último mes, vacaciones y proporcionales de la décima tercera y cuarta remuneración.

Este caso fue denunciado en redes sociales y debido a la presión pública, la empresa se vio obligada a llegar a un acuerdo extrajudicial, explicó una de las hijas del extrabajador. Grand Hotel Guayaquil no ha pagado impuesto a la renta desde el año 2009 y sus accionistas son Peder Jacobson y la empresa Corpthor S.A, que en conjunto han sacado del país cerca de 4 millones de dólares, desde el año 2017, según el Servicio de Rentas Internas.

\section{e. Florícolas}

Varios casos de despidos de trabajadores patrocinan la abogada laboral Vanessa Velásquez, uno de ellos, la terminación del contrato individual por fuerza mayor de un cliente que recibió $\$ 0,22$ de liquidación de una florícola. Afirma que del $100 \%$ de los casos, solo al $20 \%$ se les ha cancelado las actas de finiquito.

Mientras que el abogado laboral Carlos Araujo tiene cerca de 300 casos, en algunos de ellos, son de extrabajadores con 10, 15 y 25 años de trabajo que están recibiendo $\$ 800$ de liquidación. "Eso es un abuso del derecho", expresa. Velásquez y Araujo explican que aquellas personas que le terminan el contrato bajo la causal sexta del artículo 169 no reciben bonificación de desahucio ni indemnización de despido, ni ninguna otra. 


\section{f. Prefectura del Guayas}

La prefectura del Guayas despedirá a cientos de sus empleados como parte de una de las primeras decisiones de la prefecta Susana González. Algunos fueron cesados en sus funciones y otros fueron separados por la terminación de sus contratos ocasionales. 360 empleados de la Prefectura del Guayas recibieron notificaciones de despido y dejarán sus puestos hasta el martes 30 de junio de 2020. En la lista a la que tuvo acceso este Diario constan altos cargos de las direcciones de Compras Públicas, Planificación, Gestión Financiera, Administrativa, Presupuesto, Talento Humano, Procuraduría Síndica, Obras Públicas, Supervisión y Fiscalización. La nómina total representaba USD 534997 en pago mensual de salarios.

\section{Despidos Intempestivos: Provincias}

El Ministerio de Trabajo registra 9175 actas de finiquito a nivel nacional por despido intempestivo desde el 12 de marzo, es decir, un día después que se declarara la emergencia sanitaria en el país. Hasta el 27 de mayo, Pichincha se convierte en la provincia con más trabajadores despedidos con 3529. Le sigue Guayas con 2846 colaboradores.

En las demás Provincias:

Tabla 2. Despidos Intempestivos por provincias

\begin{tabular}{lc}
\hline \multicolumn{1}{c}{ Provincia } & N. $^{\text {o }}$ Empleados despedidos \\
\hline Orellana & 721 \\
Azuay & 401 \\
Tungurahua & 281 \\
Manabí & 277 \\
El Oro & 155 \\
Sto. Domingo de los Tsáchilas & 148 \\
Galápagos & 115 \\
Esmeraldas & 191 \\
Los Ríos & 182 \\
Loja & 175 \\
Chimborazo & 150 \\
Cotopaxi & 120 \\
Napo & 50 \\
Sta. Elena & 45 \\
Sucumbíos & 29 \\
Carchi & 26 \\
Cañar & 24 \\
Zamora Chinchipe & 20 \\
\hline
\end{tabular}

Elaborado por : Grupo de investigación 


\section{Despidos Intempestivos: Edades}

Hay casos de personas que tenían 18 o 19 años de servicio, cumpliendo la edad de 55 años cercanas a cobrar la jubilación patronal. Lo que se ha dicho es que a los trabajadores que son parte de algún grupo de atención prioritaria se los debe proteger, mediante el teletrabajo o ubicándolos en actividades en las que no estén expuestos.

Pero las empresas hacen caso omiso y a continuación la siguiente tabla.

\section{Datos Estadísticos}

Tras la declaración de emergencia sanitaria debido al virus de rápida propagación COVID19 , se han tomado distintas medidas para salvaguardar la salud e integridad de los ciudadanos del territorio ecuatoriano, entre ellas podemos destacar el estado de excepción dentro de todo el país y el cambio a la modalidad de teletrabajo en todas las instituciones públicas y privadas.

Frente a la situación actual y para no afectar la economía de las empresas ni de los hogares que son tan vulnerables a la actual situación que atraviesa el mundo entero, considerando que es un hecho que afecta a todos los sectores, y por sus repercusiones sociales y económicas, los empleadores pueden preferir otras opciones como el teletrabajo regulada a través del acuerdo ministerial MDT-2020-076 del 12 de marzo de 2020, o la reducción, modificación o suspensión emergente de la jornada laboral contemplada a través del del acuerdo MDT2020-077 del 15 de marzo de 2020. (Peñafiel, 2020).

Es evidente que en todo el planeta tierra y en nuestro Ecuador, se halla en una etapa de anormalidad por una adversidad pública en todo la zona nacional por los múltiples casos de COVID-19 confirmados, así como lo manifestado por la Organización Mundial de la Salud y la declaratoria de pandemia de covid-19, es decir nos encontramos ante una situación de carácter externa imprevisible e irresistible, más ante esta situación, como se expresó en líneas anteriores se emitieron dos Acuerdos Ministeriales, que tienen como fin establecer circunstancias extraordinarias de jornadas de trabajo, con el fin de preservar la estabilidad de trabajadores, otorgando a los empleadores la potestad de reducir, modificar y suspender la jornadas de trabajo, al respecto es importante remitimos al Acuerdo Ministerial Nro. 0001262020, del 11 de marzo del 2020, donde Ministerio de Salud Pública, declaró "el Estado de Emergencia Sanitaria en todos los establecimientos del Sistema Nacional de Salud, por la inminente posibilidad del efecto provocado por el Coronavirus (COVID-19) y prevenir un posible contagio masivo en la población". (Buenaño, 2020)

Referente a los despidos durante la emergencia sanitaria, el Ministro de Trabajo de Ecuador, Luis Arturo Poveda, aseguró este 31 de marzo del 2020 que "la Cartera está tomando nota a diario de las denuncias que se reciben a través del Sistema Único de Trabajo. Nuestro cuerpo de inspectores en las 24 provincias está activado diariamente para verificar las denuncias en el lugar de trabajo y elevar los informes correspondientes" (Negocios, 2020). Además, acotó 
que el Sistema Único de Trabajo ha registrado, desde que se decretó la emergencia sanitaria hasta este martes 31 de marzo, 458 denuncias de despidos intempestivos "y se han realizado 97 inspecciones focalizadas" (Negocios, 2020)

Para los primeros días de abril ya se registraban por lo menos 500 denuncias por despidos intempestivos durante de emergencia sanitaria, según reportes del Ministerio de Trabajo. (Torres, 2020)

Para fines de marzo, 6.027 empresas en el territorio ecuatoriano ya se habían acogido a las modalidades de restricción, reducción o modificación emergente de la jornada laboral. De estas empresas y en base al análisis de sus necesidades; 684 optaron por la reducción de la jornada de alrededor de 26 mil colaboradores, 488 empresas registraron modificación emergente de la jornada para más de ocho mil trabajadores, 4.855 empresas siendo la mayoría del total, acogieron la suspensión de la jornada con una suma de más de 89 mil trabajadores. Cabe destacar que la suspensión de la jornada laboral no implica directamente una finalización de la relación laboral, pues las horas suspendidas serán recuperadas a posterior. (Ministerio del Trabajo, 2020)

Ilustración 1 : Porcentaje de los trabajadores afectados

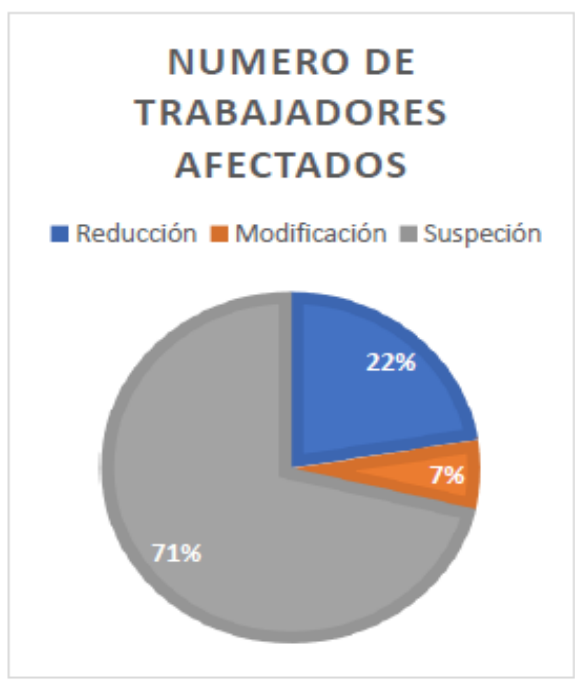

Ilustración 2: Porcentaje empresas acogidas a diferentes modalidades de trabajo

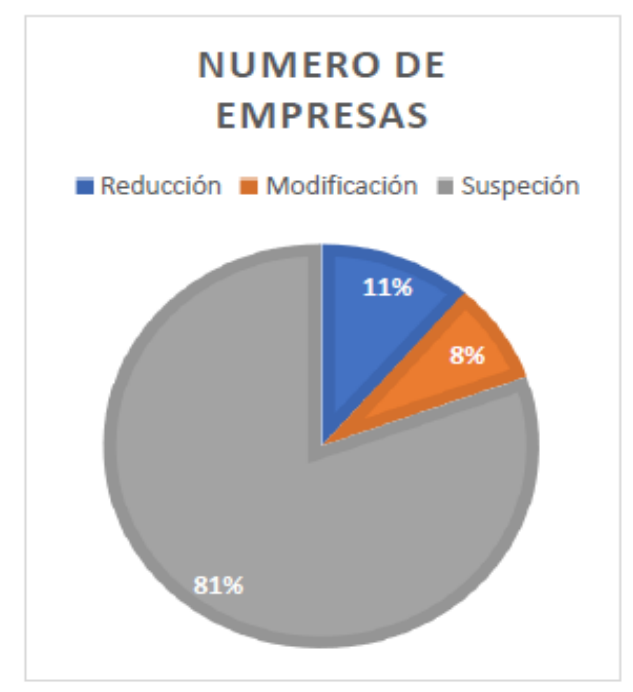

Elaborado por: Grupo de investigación

A lo largo de la emergencia sanitaria y hasta los primeros días de mayo el Ministerio de Trabajo registró 66400 desvinculaciones laborales por distintas causas. 
La mayor parte de las desvinculaciones, 38333 casos, son por mutuo acuerdo; 5883 por terminación de contrato; 3987 por despido intempestivo; por causas legalmente previstas en el contrato, 3277; por muerte del trabajador 101. Además, por muerte o incapacidad del empleador hay 63 actas de finiquito; por voluntad del empleador antes del visto bueno, 44 casos; por terminación del contrato antes del periodo convenido, 20; y, por voluntad del trabajador, 8 casos. (Política, 2020)

Ilustración 3: Empleados Trabajadores en modalidad teletrabajo

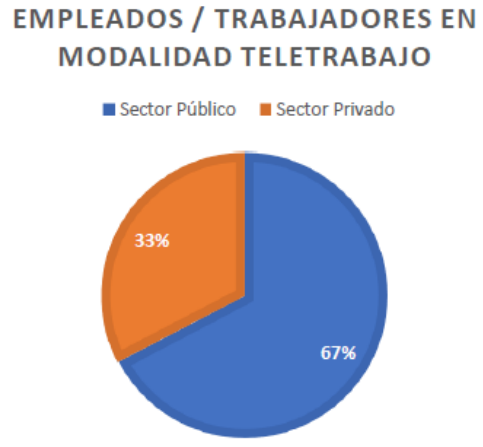

Elaborado por: Grupo de investigación

Para mediados del mes de junio el Ministro del Trabajo compareció en la Comisión de los Derechos de los Trabajadores y Seguridad Social de la Asamblea Nacional. "Necesitamos mecanismos que permitan llegar a acuerdos entre trabajadores y empleadores para preservar las fuentes de empleo y la sostenibilidad de las empresas", indicó.

Ilustración 4: Estadística de terminación del contrato laboral en el mes de Junio TERMINACIÓN DEL CONTRATO

- Mutuo Acuerdo = Caso fortuito/fuerza mayor a despidos intempestivos = Otros

JUNIO, 2020

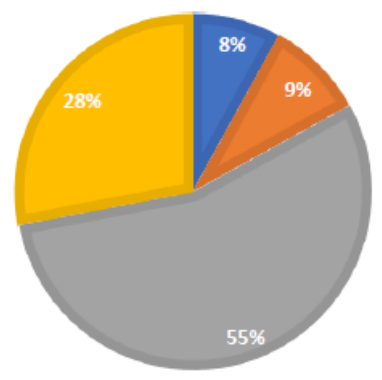

Elaborado por: Grupo de investigación

Al momento existen 425.424 trabajadores en la modalidad de teletrabajo, de los cuales 286.401 pertenecen al sector público y 139.023 al sector privado. Asimismo, indicó que en el Sistema Único de Trabajo-SUT se han registrado 180.852 terminaciones de contratos de 
trabajo, de los cuales el 55\% se han dado por acuerdo entre las partes, el 9\% por la aplicación de caso fortuito o fuerza mayor y el $8 \%$ por despidos intempestivos. (Ministerio del Trabajo, 2020)

Ilustración 5: Desvinculaciones laborales en el mes de mayo

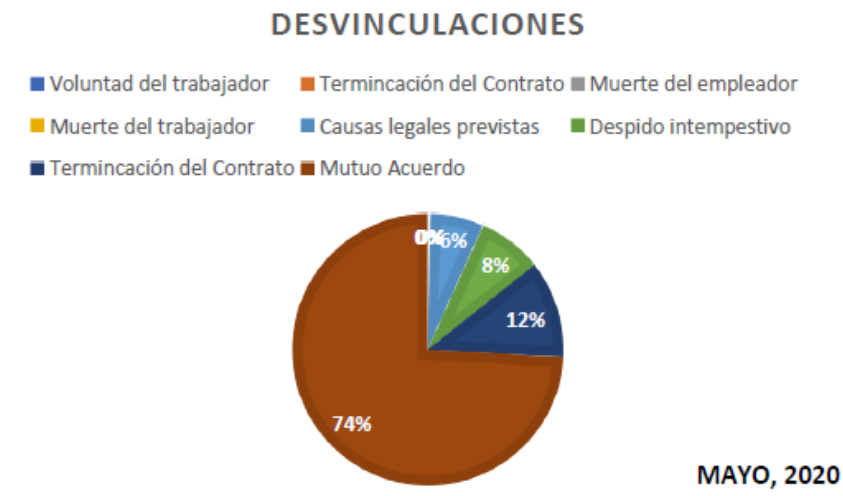

Elaborado por: Grupo de investigación

\section{Discusión}

La pandemia mundial del COVID-19 afecta las tendencias vigentes en los mercados laborales estos impactos se mantendrían, con acento cambiante, por lo que resta del año, es dable que cierta cantidad de empleos no se recuperen, aun en un contexto encomiástico de reactivación económica, luego que otras acciones se revelarán, de manera que la evocación de la división en los países sur americanos en los que se encuentra el país, cambiará respecto a la circunstancia previa al desconfinamiento y cese de la pandemia. La reactivación promisoria de los procesos de trabajo se verá activa cuando el gobierno y las personas puedan vincularse al sector laboral estatal o a su vez realizar micro negocios propios

\section{Conclusiones.}

- Ecuador está atravesando circunstancias muy críticas incluyendo las empresas, algunas de ellas han tendido que cerrar por fuerza mayor y eso ha ocasionado el incremento del índice desempleo, es necesario tomar medidas correctivas que ayuden a mejor la situación socioeconómica del país.

- El cierre de mercados a causa de la pandemia de coronavirus ha llevado al sector florícola a solicitar al Gobierno la autorización para otorgar licencias extensivas a los trabajadores para evitar recortes de personal. Se busca otorgar 90 días de licencia laboral sin remuneración ni pago de la Seguridad Social.

- Los despidos actuales son justificados como intempestivos y por ende se debe cancelar la indemnización equivalente a un sueldo por cada año, más el 25 por ciento de sueldo por cada año por bonificación de desahucio, establecido en el Código de Trabajo. 
- Los empleadores que pretendan terminar una relación laboral pueden sustentarse en la causal 6 del artículo 169 del código de trabajo, caso fortuito o fuerza mayor. No obstante, deberán prever un posible conflicto legal si esta norma se aplica de manera incorrecta. Puesto que, la norma ampara los derechos de los trabajadores; y, al optar por esta causa el empleador debe dimensionar el efecto del estado de emergencia y la crisis, como situación general que impedida de forma definitiva continuar con la actividad económica, tomando en cuenta que deberá probar que su situación particular dio un giro a la actividad y alcanza para considerarse fuerza mayor o caso fortuito.

- Las empresas que han optado por terminar el contrato de trabajo acogiendo el artículo 169 del código de trabajo, una vez que la crisis actual cese, deberán responder por las indemnizaciones que no se están realizando hacia su personal, siendo una posible negativa a largo plazo, razón por la que el ministerio recomendó no acoger esta disposición para finalizar el contrato.

- El Ministerio del Trabajo en conjunto con la Presidencia de la República hace una justa vigilancia en cuestión de los derechos laborales de los trabajadores, las fuentes de empleo, y la reactivación del sistema productivo y económico del país.

\section{Referencias Bibliográficas}

Buenaño, R. (6 de Mayo de 2020). Derecho Ecuador.com. Obtenido de https://www.derechoecuador.com/caso-fortuito-y-fuerza-mayor-dentro-de-larelacion-laboral-frente-al-covid-19: https://www.derechoecuador.com/caso-fortuitoy-fuerza-mayor-dentro-de-la-relacion-laboral-frente-al-covid-19

Cardona-Areanas \& Serna-Gómez. (3 de 4 de 2020). COVID-19 y precios del petróleo: efectos sobre el tipo de cambio del peso colombiano. Obtenido de https://papers.ssrn.com/sol3/papers.cfm?abstract_id=3567942: https://papers.ssrn.com/sol3/papers.cfm?abstract_id=3567942

CEPAL. (2020). La pandemia del COVID-19 y su efecto en las tendencias de los mercados laborales. Obtenido de https://repositorio.cepal.org/bitstream/handle/11362/45759/S2000387_es.pdf?seque nce $=1 \&$ isAllowed=y: https://repositorio.cepal.org/bitstream/handle/11362/45759/S2000387_es.pdf?seque nce $=1 \&$ isAllowed $=\mathrm{y}$

Código de Trabajo. (19 de mayo de 2017). CODIFICACION DEL CODIGO DEL TRABAJO. Quito, Pichincha: H. Congreso Nacional .

DerechoEcuador. (2020). Causales de suspension del contrato laboral. Obtenido de. Obtenido de https://www.derechoecuador.com/suspension-del-contrato-de-trabajo: https://www.derechoecuador.com/suspension-del-contrato-de-trabajo 
E.U. (13 de Abril de 2020). Las empresas que apliquen el artículo 169 para despedir a empleados deben informar al Ministerio de Trabajo. Obtenido de https://www.eluniverso.com/noticias/2020/04/13/nota/7812150/codigo-trabajoacuerdo-ministerial-fuerza-mayor-caso-fortuito: https://www.eluniverso.com/noticias/2020/04/13/nota/7812150/codigo-trabajoacuerdo-ministerial-fuerza-mayor-caso-fortuito

Fedesarrollo. (2020). Informe Mensual del Mercado Laboral - enero de 2020. Obtenido de https://www.fedesarrollo.org.co/content/informe-mensual-del-mercado-laboralenero-de-2020: https://www.fedesarrollo.org.co/content/informe-mensual-delmercado-laboral-enero-de-2020

INEC. (2010). Estadisticas y Censos. Quito .

Jácome, G. (4 de mayo de 2020). Empresas y trabajadores: entre los más impactados por el coronavirus en Ecuador. Obtenido de. Obtenido de https://www.voanoticias.com/coronavirus/coronavirus-ecuador-desempleo: https://www.voanoticias.com/coronavirus/coronavirus-ecuador-desempleo

Ministerio del Trabajo, (. M. (18 de JUNIO de 2020). http://www.trabajo.gob.ec/esnecesario-generar-mecanismos-legales-que-permitan-preservar-el-trabajo/. http://www.trabajo.gob.ec/es-necesario-generar-mecanismos-legales-que-permitanpreservar-el-trabajo/, pág. oBTENIDO http://www.trabajo.gob.ec.

Mundial, B. (2008). Informe sobre el crecimiento. Obtenido de http://documents1.worldbank.org/curated/en/282811468321254594/pdf/449860PU B0SPAN101OFFICIAL0USE0ONLY1.pdf: http://documents1.worldbank.org/curated/en/282811468321254594/pdf/449860PU B0SPAN101OFFICIAL0USE0ONLY1.pdf

Negocios. (31 de Marzo de 2020). Covid-19 en Ecuador: ¿Qué pasa este fin de mes en Ecuador con los salarios y denuncias de despidos en emergencia? Covid-19 en Ecuador: ¿Qué pasa este fin de mes en Ecuador con los salarios y denuncias de despidos en emergencia?, págs. El Comercio, pág. Online. Obtenido de https://www.elcomercio.com/actualidad/poveda-ministerio-cadenacovid19.html?fbclid=IwAR1VbR5B5EiVx5yusANVP11wqGmazmsTFFr_iwRY_mPi1y7vx15yNAJoSM.

Peñafiel, G. (8 de Abril de 2020). ILP Global: Gallegos Valarzo \& Neira. Obtenido de https://gvn.com.ec/2020/04/08/contrato-caso-fortuito-gvn/: https://gvn.com.ec/2020/04/08/contrato-caso-fortuito-gvn/ 
Política, E. (7 de Mayo de 2020). Ministerio de Trabajo:. Se han registrado 66440 desvinculaciones en lo que va de la emergencia por el COVID-19., págs. El Universo, pág. Online.

Tapia, E. (31 de marzo de 2020). Terminación de contrato laboral por fuerza mayor aplica solo si la empresa dejo de operar. Terminación de contrato laboral por fuerza mayor aplica solo si la empresa dejo de operar., págs. 1-2.

Thomas, H. (6 de junio de 2020). Pandemic, poverty, and power in global exploitation chains. Futures of Work. Obtenido de https://futuresofwork.co.uk/2020/06/05/pandemic-poverty-and-power-in-globalexploitation-chains/: https://futuresofwork.co.uk/2020/06/05/pandemic-poverty-andpower-in-global-exploitation-chains/

Torres, W. (7 de Abril de 2020). ¿Pueden las empresas usar la fuerza mayor para despedir trabajadores? . El Comercio , págs. Primicias, pág. Online.

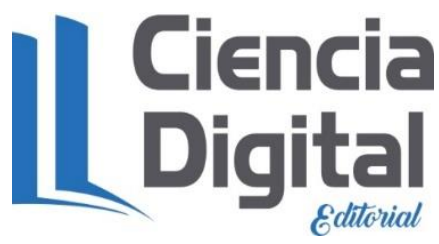




\section{PARA CITAR EL ARTÍCULO INDEXADO.}

Niama Rivera, L. M., Villalva Heredia, C. I., Terán Pérez, M. P., \& Campos Collaguazo, E. F. (2020). El cese de relación laboral en Ecuador por causa del Covid 19. ConcienciaDigital, 3(3.1), 212-228. https://doi.org/10.33262/concienciadigital.v3i3.1.1381

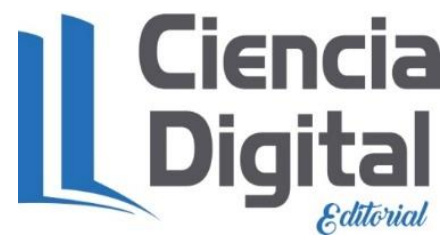

El artículo que se publica es de exclusiva responsabilidad de los autores y no necesariamente reflejan el pensamiento de la Revista Conciencia Digital.

El artículo queda en propiedad de la revista y, por tanto, su publicación parcial y/o total en otro medio tiene que ser autorizado por el director de la Revista Conciencia Digital.

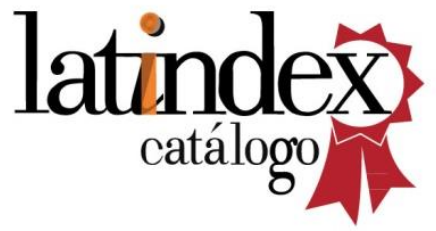

